\title{
ARTIFICIAL NEURAL NETWORK MODELING OF GRINDING OF DUCTILE CAST IRON USING WATER BASED $\mathrm{SiO}_{2}$ NANOCOOLANT
}

\author{
M.M. Rahman, K. Kadirgama and Azma Salwani Ab Aziz \\ Faculty of Mechanical Engineering \\ Universiti Malaysia Pahang \\ 26600 Pekan Pahang, Malaysia \\ Email: mustafizur @ump.edu.my \\ Phone: +6094246239; Fax: +6094246222
}

\begin{abstract}
This paper presents optimization of the grinding progress of ductile cast iron using water-based $\mathrm{SiO}_{2}$ nanocoolant. Conventional and water-based nanocoolant grinding was performed using a precision surface grinding machine. The study is aimed to investigate the effect of table speed and depth of cut on the surface roughness and material removal rate (MRR). Mathematical modeling is developed using the response surface method. An artificial neural network model is developed for predicting the surface roughness and MRR. Multi-layer perception and a batch back propagation algorithm are used. MLP is a gradient descent technique to minimize the error through a particular training pattern in which it adjusts the weight by a small amount at a time. From the experiment, the depth of cut is directly proportional to the surface roughness, but the table speed is inversely proportional to the surface roughness. The higher the value of the depth of cut, the lower the value of MRR, and vice versa for the table speed. It is concluded that the surface quality together with the material removal rate are the most affected by the depth of cut(s) and table speed.
\end{abstract}

Keywords: Grinding, water based nanocoolant; $\mathrm{SiO} 2$, surface roughness; material removal rate; multi-layer perception; back propagation.

\section{INTRODUCTION}

Grinding is a manufacturing process with unsteady process behavior, whose complex characteristics determine the technological output and quality (Krajnik, Kopac, \& Sluga, 2005; Malkin \& Guo, 2007). Grinding is actually a finishing process used to improve surface finish, abrade hard materials, and tighten the tolerance on flat and cylindrical surfaces by removing a small amount of material. A cylindrical grinding machine rotates the workpiece as the cutting tool feeds into it. The material removal rate (MRR) depends largely on the machine current and the spark on time in the cutting process (Hussein, Sharma, Bakar, \& Kadirgama, 2013; Khan, Rahman, Kadirgama, \& Bakar, 2012b; Krajnik et al., 2005; Najiha, Rahman, Kamal, Yusoff, \& Kadirgama, 2012). The speed of the material removal rate is specified on the rate of material that is being removed. The MRR is influenced by the melting temperature of the workpiece, where a lower melting temperature will gave faster MRR (Kadirgama, Abou-El-Hossein, Noor, Sharma, \& Mohammad, 2011; Khan, Rahman, Kadirgama, Maleque, \& Ishak, 2011; Noor, Kadirgama, Habeeb, Rahman, \& Mohammad, 2010; Yusoff, Mohamed Suffian, $\&$ Taib, 2011). The quality of a machined surface is characterized by the accuracy of its 
manufacture with respect to the dimensions specified by the designer. Every machining operation leaves characteristic evidence on the machined surface. This evidence is in the form of finely spaced micro irregularities left by the cutting tool. Each type of cutting tool leaves its own individual pattern which can therefore be identified. This pattern is known as surface roughness. Surface roughness is one of the most important factors for evaluating workpiece quality during the finishing process because the quality of surface affects the functional characteristics of the workpiece, such as fatigue and fracture resistance and surface friction (Samhouri \& Surgenor, 2005).

Nanofluids have the potential to be the next generation of coolants due to their significantly higher thermal conductivities (Najiha, Rahman, \& Yusoff, 2013; Najiha, Rahman, Yusoff, \& Kadirgama, 2012; Rahman \& Kadirgama, 2014; Rahman, Yusoff, \& Kadirgama, 2012). Nanofluids are formed by dispersing nanoparticles in base fluids such as water. It has been reported that the thermal conductivities of nanofluids increase dramatically due to the high thermal conductivity of solid particles suspended in the heat transfer fluid (Ding et al., 2007; Hussein, Bakar, Kadirgama, \& Sharma, 2013b; Hussein, Bakar, Kadirgama, \& Sharma, 2014). Nanofluids/nanoparticles are particles that have one dimension that is 100 nanometers or less in size. The properties of many conventional materials change when formed from nanoparticles. This is typically because nanoparticles have a greater surface area per weight than larger particles; this causes them to be more reactive to certain other molecules. Nanoparticles are used, or being evaluated for use, in many fields, especially in medication and engineering fields.

The machining process is very complex, thus experimental and analytical models that are developed by using conventional approaches such as the statistical regression technique combined with the response surface methodology (Boersma) have remained as an alternative in the modeling of the machining process. RSM is practical, economical and relatively easy to use. The experimental data was utilized to build the mathematical model for a first-and-second order model using the regression method. (Kalidass, Palanisamy, \& Muthukumaran, 2012; Khan, Rahman, \& Kadirgama, 2012a)stated that when the response can be defined by a linear function of independent variables, then the approximating function is a first-order model. An artificial neural network is a system based on the operation of biological neural networks; in other words, it emulates a biological neural system. Implementation of an artificial neural network would be necessary because, although computing nowadays is truly advanced, there are certain tasks that a program made for a common microprocessor is unable to perform. Artificial neural networks (ANN) have been developed as generalizations of mathematical models of biological nervous systems (Abraham, 2005; Khan, Rahman, Kadirgama, Maleque, \& Bakar, 2011)The objectives of this project are to investigate the experimental performance of grinding of ductile cast iron based on the response surface method, to develop an optimization model for grinding parameters using a neural network technique, and to investigate the effect of water-based $\mathrm{SiO}_{2}$ nanoparticles on precision surface grinding.

\section{MATERIALS AND METHODS}

\section{$\mathrm{SiO}_{2}$ Nanofluid Preparation}

Silicon-dioxide nanoparticle materials were selected because silicon is commonly added to the primary coolant to prevent corrosion. A two-step method was used to prepare the nanofluid; basically, nanoparticles are first produced as a dry powder, typically by inert 
gas condensation, which involves the vaporization of a source material in a vacuum chamber and subsequent condensation of the vapor into nanoparticles through collisions with a controlled pressure of an inert gas. The resulting nanoparticles are then dispersed into a fluid in a second processing step. An advantage of this technique in terms of eventual commercialization of nanofluids is that the inert gas condensation technique has already been scaled up to economically produce tonnage quantities of nanopowders. Thus, the dispersed nanoparticles come in liquid form with a volume of one liter having $25 \%$ weight concentration, with 30-40 nm particle size, $\mathrm{pH} 9$, and density equal to 2660 $\mathrm{kg} / \mathrm{m}^{3}$. This is diluted to $0.15 \%$ volume concentration. The conversion of weight percent concentration to volume concentration can be expressed as in Eq. (1). The equation shows the dilution formula to determine how much distilled water is required to dilute the initial nanofluid.

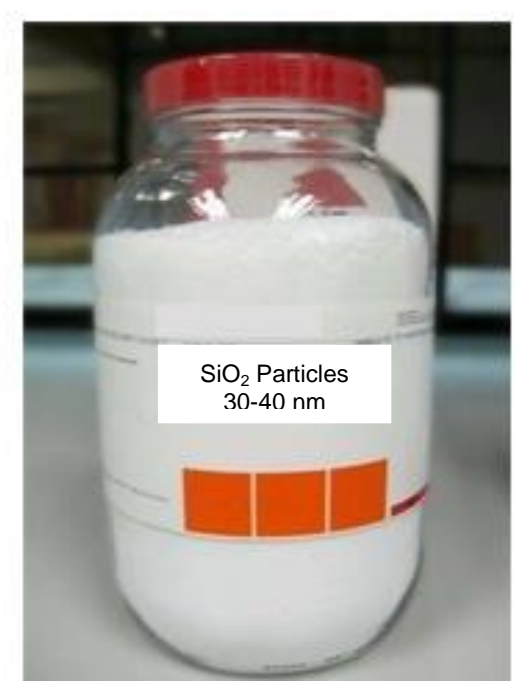

(a) $\mathrm{SiO}_{2}$ nanoparticles

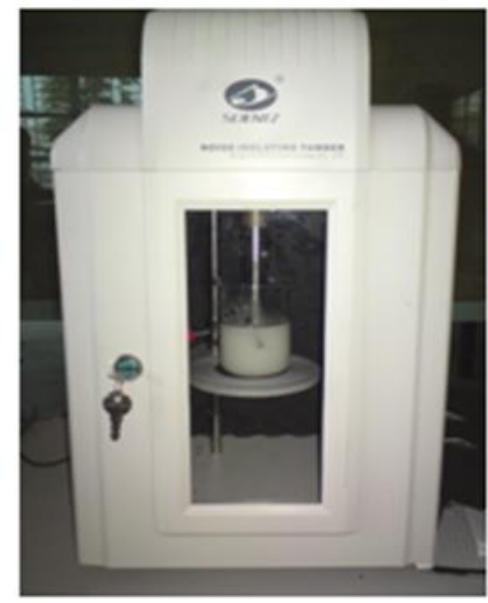

(c) Ultrasonic homogenizer

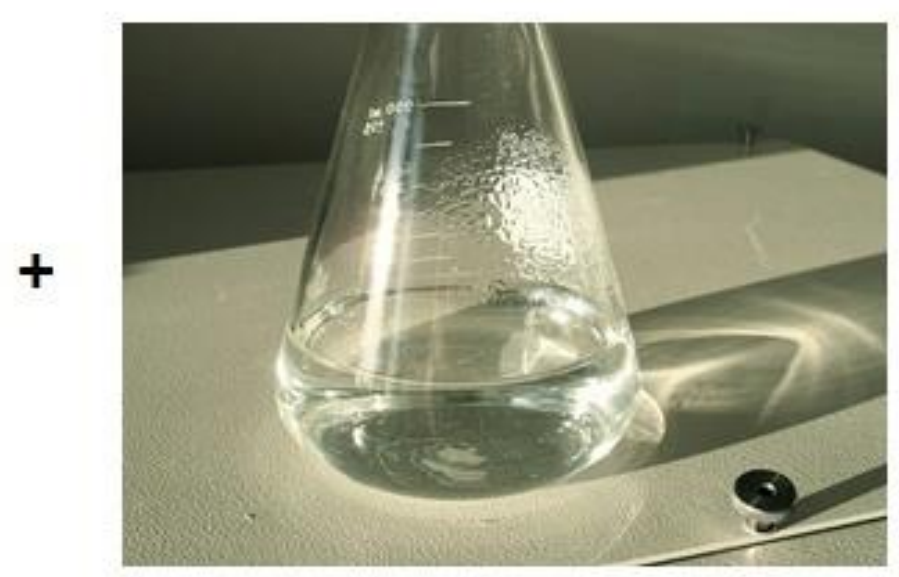

(b) Distilled water

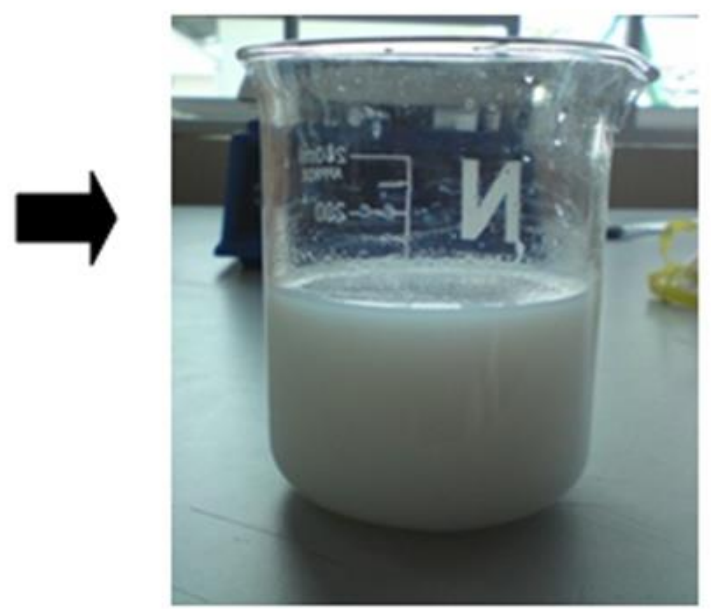

(d) Prepared $\mathrm{SiO}_{2}$ nanofluid

Figure 1. Preparation of water-based $\mathrm{SiO}_{2}$ nanocoolants 


$$
\varphi_{1}=\frac{\omega \rho_{w}}{\frac{\omega}{100} \rho_{w}+\left(1-\frac{\omega}{100}\right) \rho_{Z n O}}
$$

where

$\varphi_{1}$ is the initial volume concentration

$\omega$ is the weight percent of nanoparticles

$\rho_{w}$ is the density of water

$\rho_{Z n O}$ is the density of nanoparticles

For a two-phase system, some important issues have to be faced. One of the most important issues is the stability of nanofluids, and it remains a big challenge to achieve the desired stability. To achieve stability in dilution, it is necessary to stir the solution continuously for one hour with the mixer set to $1000 \mathrm{rpm}$. Figure 1 shows the preparation of water-based $\mathrm{SiO}_{2}$ nanocoolants. Nanoparticles have a tendency to aggregate. The important technique to enhance the stability of nanoparticles in fluids is the use of surfactants (Hussein, Bakar, Kadirgama, \& Sharma, 2013a). However, the functionality of the surfactants under high temperature is also a big concern, especially for high-temperature applications. Therefore, no surfactant is applied in this study.

\section{Design of Experiments}

Design of experiments (DOE) techniques enable designers to determine simultaneously the individual and interactive effects of many factors that could affect the output results. Statistical experimental designs (response surface designs (RSM)) are most widely used in optimization experiments (Box \& Draper, 1987; Khan et al., 2012a; Rahman, Khan, Kadirgama, Noor, \& Bakar, 2010). The central composite design (CCD) is the most popular of the many classes of RSM designs due to the following three properties (Rahman, Khan, Kadirgama, Noor, \& Bakar, 2011b).

Table 1. Design of experiment table

\begin{tabular}{ccccc}
\hline Variable symbol and & Independent & \multicolumn{3}{c}{ Levels } \\
\cline { 3 - 5 } unit & variable & -1 & 0 & +1 \\
\cline { 3 - 5 } Table speed $(\mathrm{mm} / \mathrm{s})$ & $\mathrm{X}_{1}$ & 333.33 & 500.00 & 666.67 \\
Depth of cut $(\mu \mathrm{m})$ & $\mathrm{X}_{2}$ & 0.02 & 0.04 & 0.06 \\
\hline
\end{tabular}

\section{Artificial Neural Network}

The most basic and commonly used artificial neural network (ANN) is multi-layer perception (MLP) (Rahman, Khan, Kadirgama, Noor, \& Bakar, 2011a).For this project, the gradient is determined using a technique called batch back propagation, one of the famous training algorithms for MLP, which involves performing computations backwards through the network. Once the network weights and biases are initialized, the network is ready for training. The network can be trained for function approximation, which is nonlinear regression, pattern association, and pattern classification. The training process requires a set of examples of proper network behavior network inputs and target outputs. During training, the weights and biases of the network are iteratively adjusted to minimize the network performance function. The performance function for a 
feed forward network is mean square error, which means the average squared error between the network outputs and the target outputs. All these algorithms use the gradient of the performance function to determine how to adjust the weights to minimize performance. The objective of the developed ANN is to predict the surface roughness and MRR for conventional and nanocoolant grinding. The available data set from the experimental study was divided into two sets: training and testing sets. The experimental data set consists of 9 values representing grinding passes and types of coolant. The ANN model was trained using 5 randomly selected data (accounting for $50 \%$ of the total data) while the remaining four data (accounting for $25 \%$ each) were utilized for testing and validation of the network performance. There are many variations of the batch back propagation algorithm. The simplest implementation of batch back propagation learning updates the network weights and biases in the direction in which the function decreases most rapidly, the negative of the gradient (Khan et al., $2012 b$ ). There are two different ways in which this gradient descent algorithm can be implemented: incremental mode and batch mode. In incremental mode, the gradient is computed and the weights are updated after each input is applied to the network and before the weights are updated. In batch mode, the weights and biases of the network are updated only after the entire training set has been applied to the network. The gradients calculated for each training example are added together to determine the change in the weights and biases. The primary objective in batch back propagation is to explain how to use the batch back propagation training functions in the toolbox to train the feed forward neural networks to solve specific problems. The architecture of the developed ANN model is shown in Figure 2.

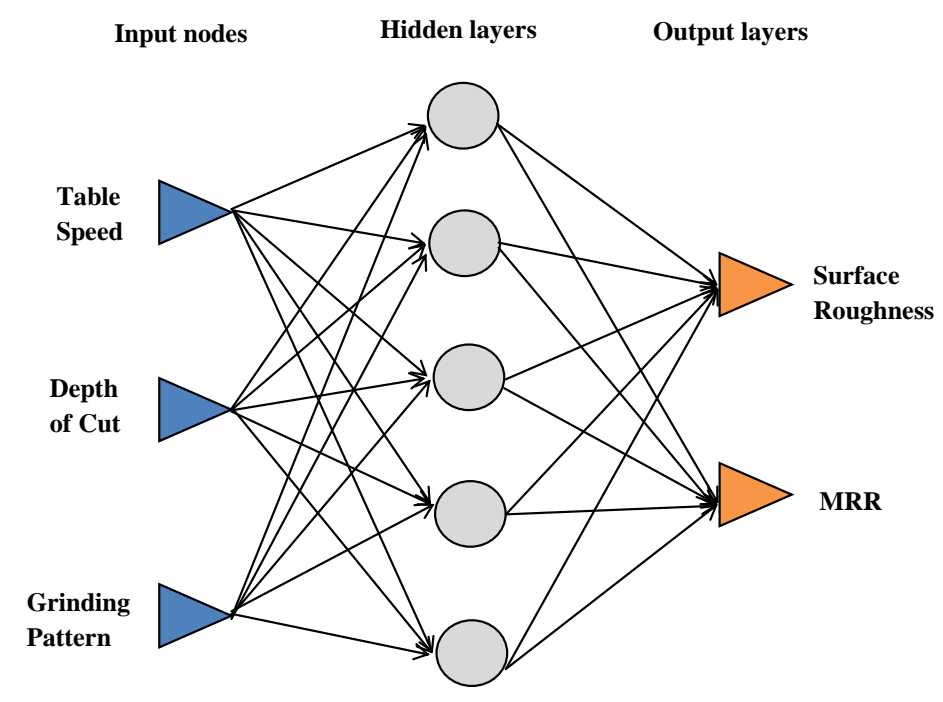

Figure 2. Architecture of the developed ANN model

\section{RESULTS AND DISCUSSION}

\section{Mathematical Modeling}

After conducting the conventional coolant and $\mathrm{SiO}_{2}$ nanocoolant grinding with single and multiple grinding patterns, the experimental data were used to find parameters appearing in the postulated second order model. RSM comprises a body of methods for exploring for the optimum operating conditions through experimental methods. Table 2 
and Table 3 present the ANOVA results for second-order modeling of MRR for conventional coolant and $\mathrm{SiO}_{2}$ nanocoolant grinding respectively. The $\mathrm{R}^{2}$ is 0.98 and the RMSE is just 0.0075. The P-values for the lack of fit for both cases are more than 0.005 . Therefore, both models are adequate and fit for analysis. The regression equation's low P-value $(<0.05)$ indicates that the model is considered to be statistically significant (Fristak, Remenarova, \& Lesny, 2012). A value of $\mathrm{P}<0.0001$ indicates the statistical significance of a quadratic model. On the basis of this investigation, the relationship between the independent variables (table speed, depth of cut) and the response (surface roughness, MRR) can be explained according to the regression model. The goodness of the model can be confirmed by the coefficients of determination $\mathrm{R}^{2}$ which are close to 1 , which are very high and indicate a high correlation between the experimental and predicted values. Figure 3(b) shows the result of single pass and multi pass conventional and water based silicon oxide nanocoolant grinding (Khan et al., 2012a). The predicted values are found to be in good agreement with the experimental readings.

Table 2. ANOVA results of second-order model for conventional grinding.

\begin{tabular}{lcccc}
\hline \multicolumn{1}{r}{ Source } & Degree of freedom & Sum of sq. & F-static & P-value \\
\hline Model & 5 & Single pass grinding & \\
Error & 4 & 0.01334571 & 47.3250 & 0.0012 \\
C total & 9 & 0.00022560 & & \\
Lack of fit & 3 & 0.01357131 & 0.5258 & 0.7383 \\
Pure error & 1 & 0.00013807 & \\
Total error & 4 & 0.00008753 & & \\
\hline & 0.00022560 & \\
\hline Model & 5 & 0.01279319 & 52.9849 & \\
Error & 4 & 0.00019316 & & \\
C total & 9 & 0.01298635 & & \\
Lack of fit & 3 & 0.00006303 & 0.1615 & \\
Pure error & 1 & 0.00013013 & & \\
Total error & 4 & 0.00019316 & & \\
\hline
\end{tabular}

Table 3. ANOVA results of second-order model for $\mathrm{SiO}_{2}$ nanocoolant.

\begin{tabular}{lcccc}
\hline \multicolumn{1}{c}{ Source } & Degree of freedom & Sum of sq. & F-static & P-value \\
\hline Model & 5 & Single pass grinding & \\
Error & 4 & 0.00342293 & 4.1484 & 0.0964 \\
C total & 9 & 0.00066010 & & \\
Lack of fit & 3 & 0.00408303 & \multirow{2}{*}{0.8625} \\
Pure error & 1 & 0.00027741 & \\
Total error & 4 & 0.00066010 & \\
\hline & 5 & & \\
\hline Model & 5 & 0.00761519 & 11.7096 & \\
Error & 4 & 0.00052027 & \\
C total & 9 & 0.00813546 & \\
Lack of fit & 3 & 0.00043078 & 1.6046 & \\
Pure error & 1 & 0.00008949 & & \\
Total error & 4 & 0.00052027 & \\
\hline
\end{tabular}


The mathematical model of the material removal rate for conventional coolant and $\mathrm{SiO}_{2}$ nanocoolant with single pass and multiple pass grinding is as follows:

$$
\begin{aligned}
& \mathrm{MRR}_{\text {Conv-singlepass }}=0.06944+0.02507 \times T S+0.03762 \times D O C \\
& +T S \times\left(D O C^{*} 0.01556\right)+T S \times(T S \times 0.00687)+D O C \times(D O C \times-0.00228) \\
& \mathrm{MRR}_{\text {Con--multiplepass }}=0.01893+-0.00163 \times T S+0.02089 \times D O C+T S \times \\
& (D O C \times 0.00067)+T S \times(T S \times-0.00447)+D O C \times(D O C \times 0.01831) \\
& \mathrm{MRR}_{\mathrm{SiO2--sin} \mathrm{glepass}}=0.07993+0.02780 \times T S+0.03521 \times D O C \\
& +T S \times(D O C \times 0.01210)+T S \times(T S \times 0.007148)+D O C \times(D O C \times-0.00351) \\
& \mathrm{MRR}_{\text {SiO2--multiplepass }}=0.40203+0.02172 \times T S+0.00027 \times D O C \\
& +T S \times(D O C \times-0.02792)+T S \times(T S \times 0.02671)+D O C \times(D O C \times-0.00397)
\end{aligned}
$$

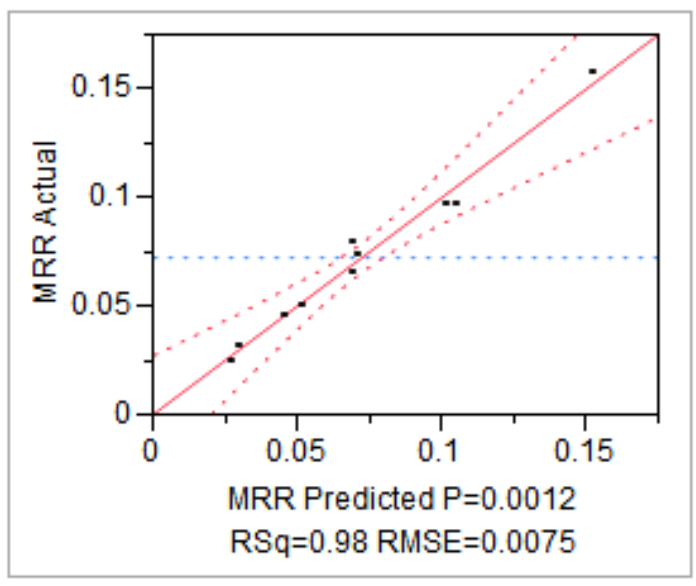

(a)

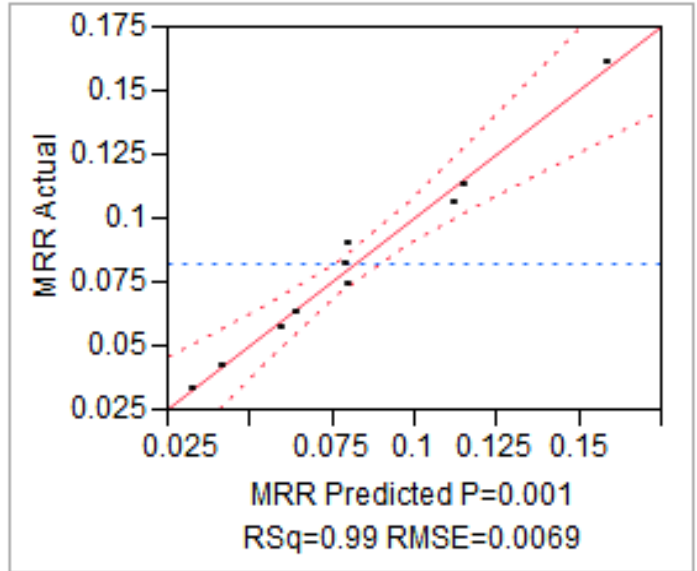

(c)

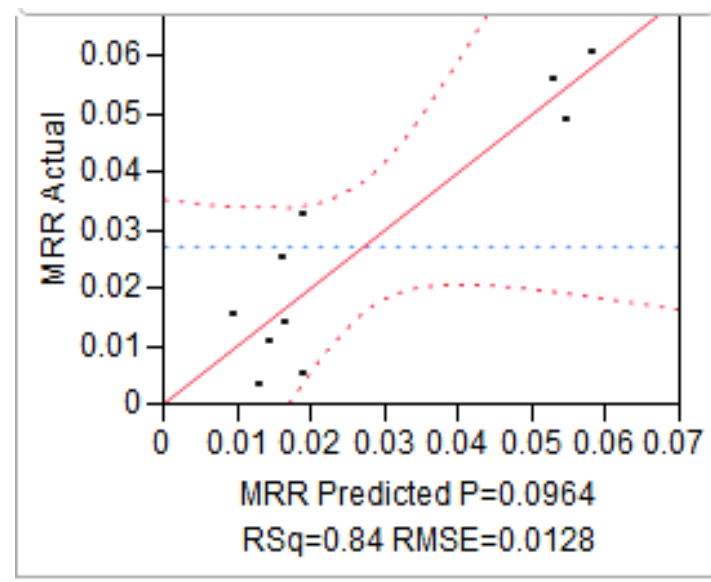

(b)

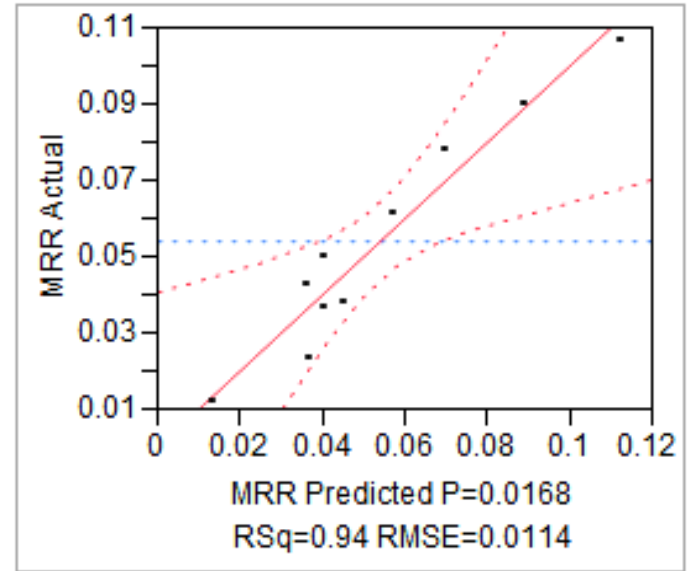

(d)

Figure 3. (a) Conventional-single pass; (b) $\mathrm{SiO}_{2}$-single pass; (c) conventional-multiple pass; (d) $\mathrm{SiO}_{2}$-multiple pass 


\section{Artificial Neural Network Modeling}

The ANN model is developed for predicting the surface roughness and MRR. The predictions of the trained ANN for depth of cut and table speed are selected. To develop the ANN model, the network is processed through two stages, which are the training stage and testing/validation stage. In the training stage, the network is tested to stop or continue training it, and it is used to predict an output. It is also used to calculate different measures of error. The network training process is stopped when the testing error is within the tolerance limits. Figure 4 shows the actual versus predicted values for conventional-single pass by ANN analysis. The blue line indicates the experimental output and the red line indicates the prediction output (target). The ANN prediction yields the statistical coefficients, giving the correlation coefficient $\left(\mathrm{R}^{2}\right)$ value 0.99 for both cases. The regression coefficients obtained from testing of the ANN were perfect and within the acceptable limits in both cases. As the correlation coefficient approaches 1 , the accuracy of the prediction advances. Thus, the correlation coefficient range is very close to 1 . Consequently, it indicates excellent agreement between the experimental and the ANN predicted results. Tables 4 and 5 present the architecture search for conventional coolant and $\mathrm{SiO}_{2}$ nanocoolant with multiple pass grinding respectively. ID 2 is selected for surface roughness and MRR prediction due to the highest $\mathrm{R}^{2}$ values.

Table 4. Architecture search for conventional coolant with multiple pass grinding

\begin{tabular}{|c|c|c|c|c|c|c|c|c|}
\hline ID & $\mathrm{N}$ & $\mathrm{F}$ & $\operatorname{TrE}$ & $\mathrm{VE}$ & $\mathrm{TE}$ & $\mathrm{C}$ & $\mathrm{R}-\mathrm{S}$ & SR \\
\hline \multicolumn{9}{|c|}{ Surface roughness } \\
\hline 1 & 1 & 0.883953 & 0.022513 & 0.004986 & 0.013174 & 0.986941 & 0.883953 & AID \\
\hline 2 & 18 & 0.998321 & 0.002172 & 0.012646 & 0.028586 & 0.999780 & 0.998321 & AID \\
\hline 3 & 11 & 0.988417 & 0.007610 & 0.016988 & 0.029194 & 0.998375 & 0.988417 & AID \\
\hline 4 & 7 & 0.979744 & 0.010036 & 0.013179 & 0.029276 & 0.997141 & 0.979744 & AID \\
\hline 5 & 15 & 0.989209 & 0.007556 & 0.020554 & 0.030841 & 0.998260 & 0.989209 & AID \\
\hline 6 & 13 & 0.987268 & 0.008047 & 0.005581 & 0.028366 & 0.997699 & 0.987268 & AID \\
\hline 7 & 16 & 0.993438 & 0.004869 & 0.009234 & 0.029381 & 0.999467 & 0.993438 & AID \\
\hline 8 & 17 & 0.989079 & 0.006394 & 0.005369 & 0.035876 & 0.998707 & 0.989079 & AID \\
\hline \multicolumn{9}{|c|}{ MRR } \\
\hline 1 & 1 & 0.991968 & 0.001431 & 0.006565 & 0.023644 & 0.998313 & 0.991968 & AID \\
\hline 2 & 18 & 0.997905 & 0.000689 & 0.005742 & 0.019354 & 0.999538 & 0.997905 & AID \\
\hline 3 & 11 & 0.997393 & 0.000797 & 0.005898 & 0.020232 & 0.999374 & 0.997393 & AID \\
\hline 4 & 7 & 0.995553 & 0.001062 & 0.005858 & 0.021403 & 0.998847 & 0.995553 & AID \\
\hline 5 & 15 & 0.997747 & 0.000720 & 0.002203 & 0.016833 & 0.999494 & 0.997747 & AID \\
\hline 6 & 13 & 0.996744 & 0.000884 & 0.001452 & 0.016369 & 0.999219 & 0.996744 & AID \\
\hline 7 & 16 & 0.996340 & 0.000959 & 0.000725 & 0.010336 & 0.999101 & 0.996340 & AID \\
\hline 8 & 14 & 0.997379 & 0.000795 & 0.002581 & 0.015343 & 0.999381 & 0.997379 & AID \\
\hline
\end{tabular}

Note: $\mathrm{N}=$ Neurons, $\mathrm{F}=$ Fitness, $\mathrm{TEr}=$ Training error, $\mathrm{VE}=$ Validation error, $\mathrm{TE}=$ Testing error, $\mathrm{C}=$ Correlation, $\mathrm{R}-\mathrm{S}=\mathrm{R}$-square, $\mathrm{SR}=\mathrm{Stop}$ reason, $\mathrm{AID}=$ All iterations done

\section{Optimization}

From the experimental and analysis results for single and multi pass conventional grinding, the minimum surface roughness and maximum MRR were chosen from all of 
the data. From the data, two values of the lowest surface roughness were carried out from each analysis since surface roughness is most prior than MRR which is 0.204 and 0.250 for $1^{\text {st }}$ order of RSM, 0.186 and 0.247 for $2^{\text {nd }}$ order of RSM, and also 0.237 and 0.317 for RBF. Of the two values of the surface roughness, the one with the higher MRR value was chosen. So, we can conclude that the table speed $666.67 \mathrm{~mm} / \mathrm{s}$ with 0.02 $\mu \mathrm{m}$ depth of cut is the best optimized value that can be used for single pass conventional grinding. Comparisons between the RSM model and ANN for conventional coolant and $\mathrm{SiO} 2$ nanocoolant are presented in Tables 6 and 7 respectively.

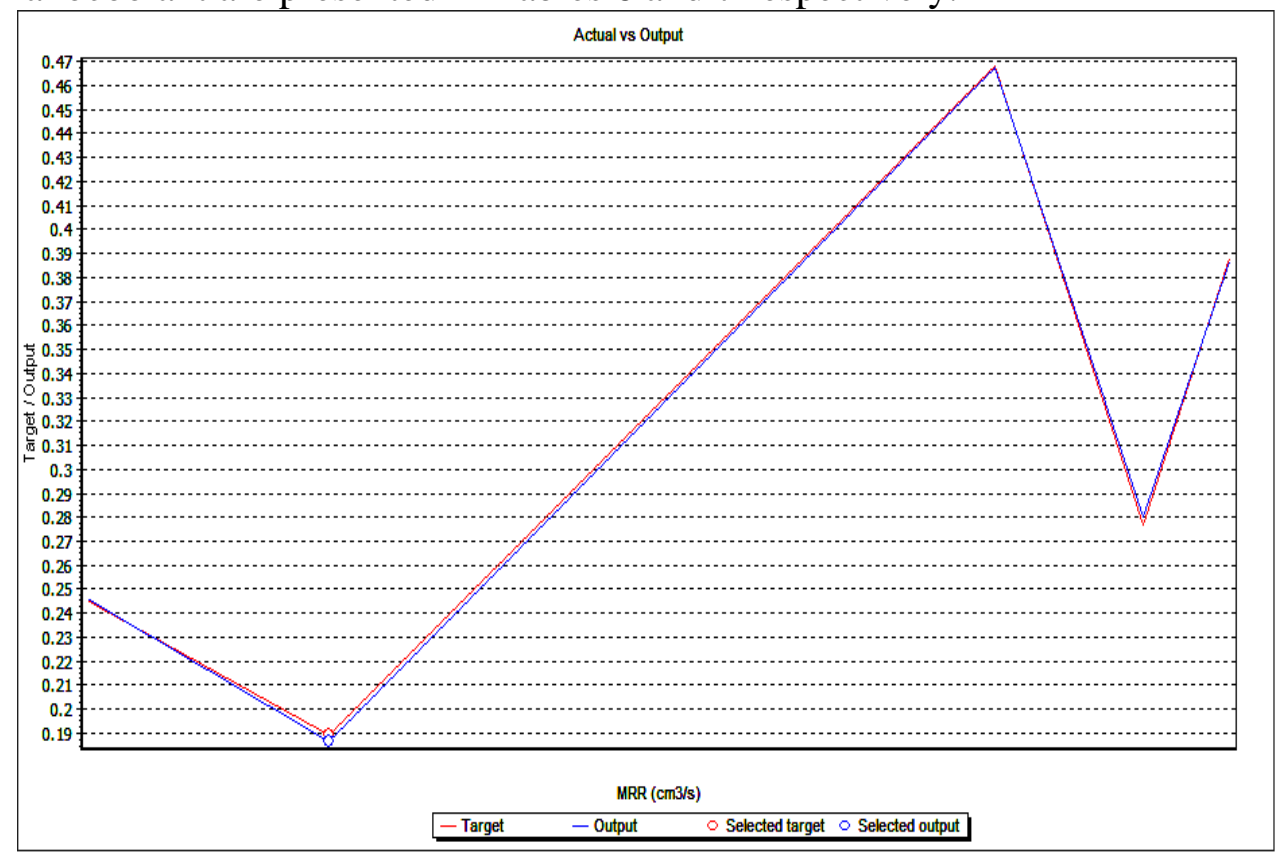

(a) Surface roughness

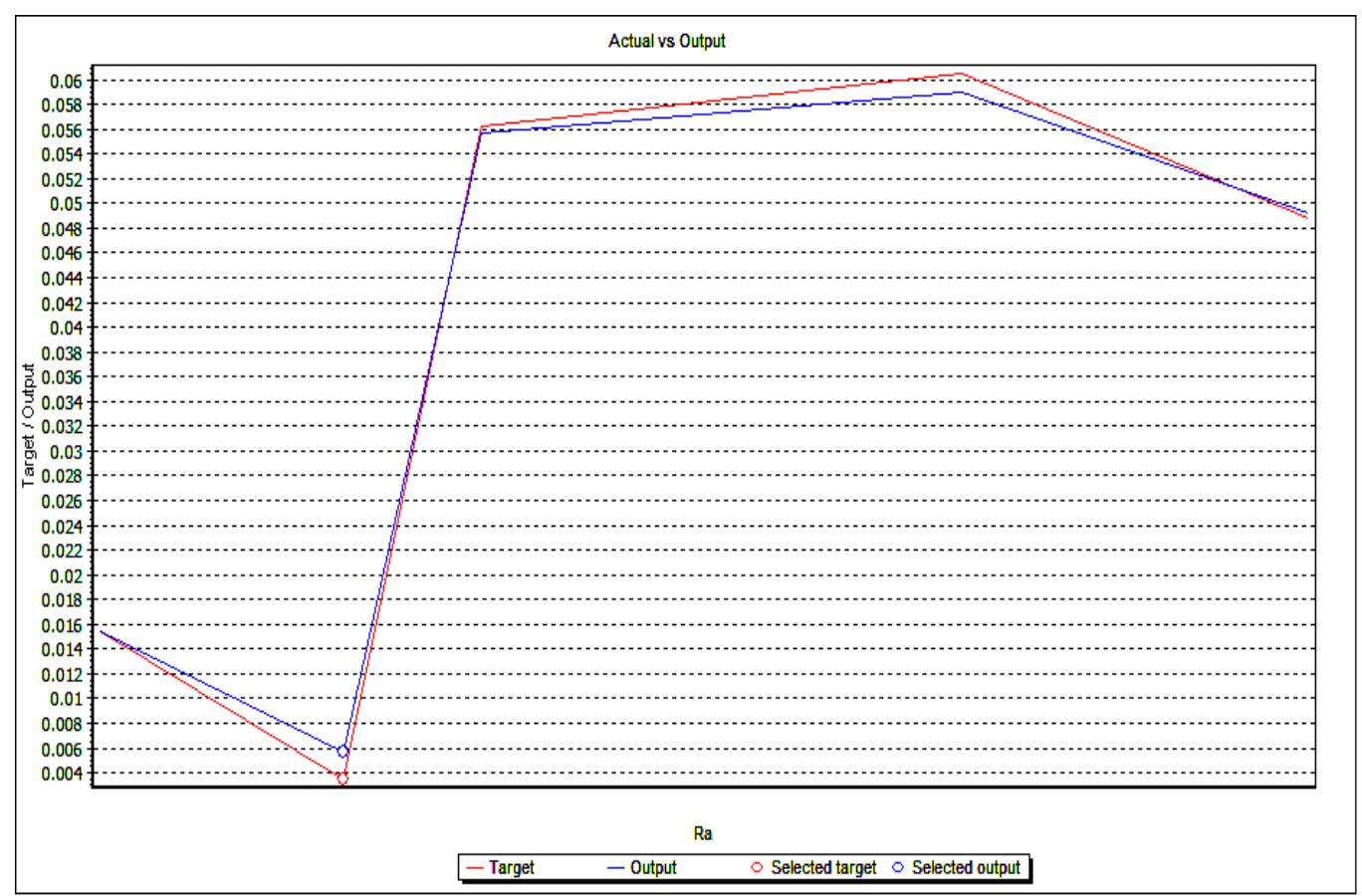

(b) MRR

Figure 4. Actual versus predicted values for $\mathrm{SiO}_{2}$-single pass 
Table 5. Architecture search for $\mathrm{SiO}_{2}$ nanocoolant with multiple pass grinding

\begin{tabular}{|c|c|c|c|c|c|c|c|c|}
\hline ID & $\mathrm{N}$ & $\mathrm{F}$ & TrE & VE & TE & $\mathrm{C}$ & R-S & SR \\
\hline \multicolumn{9}{|c|}{ Surface roughness } \\
\hline 1 & 1 & 0.952358 & 0.008931 & 0.018053 & 0.037088 & 0.984222 & 0.952358 & AID \\
\hline 2 & 18 & 0.995183 & 0.002422 & 0.024921 & 0.031183 & 0.999099 & 0.995183 & AID \\
\hline 3 & 11 & 0.984284 & 0.005360 & 0.016197 & 0.013763 & 0.996549 & 0.984284 & AID \\
\hline 4 & 7 & 0.982542 & 0.005600 & 0.020976 & 0.022371 & 0.996423 & 0.982542 & AID \\
\hline 5 & 15 & 0.990264 & 0.003976 & 0.020695 & 0.024468 & 0.998350 & 0.990264 & AID \\
\hline 6 & 13 & 0.990996 & 0.003833 & 0.022881 & 0.017140 & 0.998422 & 0.990996 & AID \\
\hline 7 & 14 & 0.989989 & 0.004026 & 0.009807 & 0.025953 & 0.998105 & 0.989989 & AID \\
\hline 8 & 12 & 0.988438 & 0.004399 & 0.007814 & 0.011753 & 0.998019 & 0.988438 & AID \\
\hline \multicolumn{9}{|c|}{ MRR } \\
\hline 1 & 1 & -0.315868 & 0.028451 & 0.006431 & 0.028397 & 0.160204 & 0.315868 & AID \\
\hline 2 & 18 & 0.628088 & 0.014661 & 0.005098 & 0.042006 & 0.913600 & 0.628088 & AID \\
\hline 3 & 11 & 0.790516 & 0.011528 & 0.003650 & 0.055038 & 0.971231 & 0.790516 & AID \\
\hline 4 & 7 & 0.966930 & 0.004116 & 0.010974 & 0.073012 & 0.992002 & 0.966930 & AID \\
\hline 5 & 4 & 0.434784 & 0.019056 & 0.011107 & 0.048682 & 0.849345 & 0.434784 & AID \\
\hline 6 & 9 & 0.897173 & 0.008106 & 0.008975 & 0.066582 & 0.983870 & 0.897173 & AID \\
\hline 7 & 5 & 0.307026 & 0.020752 & 0.005979 & 0.043788 & 0.739724 & 0.307026 & AID \\
\hline 8 & 8 & 0.460940 & 0.019919 & 0.008800 & 0.042534 & 0.828332 & 0.460940 & AID \\
\hline 9 & 6 & -0.51821 & 0.032062 & 0.009124 & 0.023176 & 0.551642 & -0.51821 & AID \\
\hline
\end{tabular}

Note: $\mathrm{N}=$ Neurons, $\mathrm{F}=$ Fitness, $\mathrm{TrE}=$ Training error, $\mathrm{VE}=$ Validation error, $\mathrm{TE}=$ Testing error, $\mathrm{C}=$ Correlation, $\mathrm{R}-\mathrm{S}=\mathrm{R}$-square, $\mathrm{SR}=\mathrm{Stop}$ reason, $\mathrm{AID}=$ All iterations done

Table 6. Comparison between RSM model and ANN for conventional coolant

\begin{tabular}{|c|c|c|c|c|c|c|c|c|c|}
\hline \multirow{3}{*}{$\begin{array}{c}\text { Table } \\
\text { speed } \\
(\mathrm{mm} / \mathrm{s})\end{array}$} & \multirow{3}{*}{$\begin{array}{l}\text { Depth } \\
\text { of cut } \\
(\mu \mathrm{m})\end{array}$} & \multicolumn{4}{|c|}{ Surface roughness } & \multicolumn{4}{|c|}{ MRR } \\
\hline & & \multirow[b]{2}{*}{ Exp. } & \multicolumn{2}{|c|}{ RSM } & \multirow[b]{2}{*}{$\mathrm{RBF}$} & \multirow[b]{2}{*}{ Exp. } & \multicolumn{2}{|c|}{ RSM } & \multirow[b]{2}{*}{ RBF } \\
\hline & & & $\begin{array}{l}1^{\text {st }} \\
\text { order }\end{array}$ & $\begin{array}{l}2^{\text {nd }} \\
\text { order }\end{array}$ & & & $\begin{array}{c}1^{\mathrm{st}} \\
\text { order }\end{array}$ & $\begin{array}{c}2^{\text {nd }} \\
\text { order }\end{array}$ & \\
\hline \multicolumn{10}{|c|}{ Single pass grinding } \\
\hline 666.67 & 0.02 & 0.151 & 0.186 & 0.170 & 0.164 & 0.046 & 0.074 & 0.049 & 0.041 \\
\hline 666.67 & 0.04 & 0.181 & 0.214 & 0.174 & 0.172 & 0.097 & 0.115 & 0.101 & 0.099 \\
\hline \multicolumn{10}{|c|}{ Multiple pass grinding } \\
\hline 666.67 & 0.02 & 0.186 & 0.218 & 0.197 & 0.191 & 0.063 & 0.079 & 0.071 & 0.065 \\
\hline 666.67 & 0.04 & 0.189 & 0.219 & 0.199 & 0.193 & 0.113 & 0.130 & 0.121 & 0.115 \\
\hline
\end{tabular}

Table 7. Comparison between RSM model and ANN for silicon oxide nanocoolant

\begin{tabular}{|c|c|c|c|c|c|c|c|c|c|}
\hline \multirow{3}{*}{$\begin{array}{c}\text { Table } \\
\text { speed } \\
(\mathrm{mm} / \mathrm{s})\end{array}$} & \multirow{3}{*}{$\begin{array}{l}\text { Depth } \\
\text { of cut } \\
(\mu \mathrm{m})\end{array}$} & \multicolumn{4}{|c|}{ Surface roughness } & \multicolumn{4}{|c|}{ MRR } \\
\hline & & \multirow[b]{2}{*}{ Exp. } & \multicolumn{2}{|c|}{ RSM } & \multirow[b]{2}{*}{ RBF } & \multirow[b]{2}{*}{ Exp. } & \multicolumn{2}{|c|}{ RSM } & \multirow[b]{2}{*}{ RBF } \\
\hline & & & $1^{\text {st }}$ order & $\begin{array}{c}2^{\text {nd }} \\
\text { order }\end{array}$ & & & $\begin{array}{c}1^{\text {st }} \\
\text { order }\end{array}$ & $\begin{array}{c}2^{\text {nd }} \\
\text { order }\end{array}$ & \\
\hline \multicolumn{10}{|c|}{ Single pass grinding } \\
\hline 666.67 & 0.02 & 0.189 & 0.244 & 0.226 & 0.217 & 0.015 & 0.040 & 0.020 & 0.017 \\
\hline 666.67 & 0.04 & 0.245 & 0.350 & 0.317 & 0.307 & 0.03 & 0.026 & 0.008 & 0.006 \\
\hline \multicolumn{10}{|c|}{ Multiple pass grinding } \\
\hline 666.67 & 0.02 & 0.238 & 0.281 & 0.240 & 0.246 & 0.107 & 0.153 & 0.112 & 0.109 \\
\hline 666.67 & 0.04 & 0.283 & 0.320 & 0.278 & 0.283 & 0.090 & 0.108 & 0.099 & 0.091 \\
\hline
\end{tabular}




\section{CONCLUSIONS}

It has become increasingly important for manufacturers to implement sustainability in tool and process design. In order to optimize the two parameters to yield the minimum surface roughness and the maximum material removal rate value in the process, a combination of knowledge of variable table speed and depth of cut parameters is crucial. The model was of an adequate fit and acceptable for sustainable grinding using $0.25 \%$ volume concentration of silicon dioxide nanocoolant. The results clearly show that the parameters used were positively correlated with the surface roughness and MRR. The $\mathrm{SiO}_{2}$ multiple pass grinding gives the best value of percentage error between the RSM and the experimental value is $0.4 \%$. The grinding process with $\mathrm{SiO}_{2}$ nanocoolant gives the best result for surface roughness and surface finish compared to conventional grinding. This paper quantifies the impact of water based $\mathrm{SiO}_{2}$ nanoparticle coolant on the achieved surface quality. It is concluded that the surface quality has the greatest impact on the depth of cut(s) and table speed.

\section{ACKNOWLEDGMENTS}

The authors would like to thank Universiti Malaysia Pahang for financial support under university research project no. RDU120310.

\section{REFERENCES}

Abraham, A. (2005). Artificial neural networks. In p. H. Sydenham \& r. Thorn (eds.), handbook of measuring system design: New York: John Wiley \& Sons.

Boersma, B. J. (2011). A 6th order staggered compact finite difference method for the incompressible navier-stokes and scalar transport equations. Journal of Computational Physics, 230(12), 4940-4954.

Box, G. E. P., \& Draper, N. R. (1987). Empirical model-building and response surfaces. : New York: John Wiley \& Sons.

Ding, Y., Chen, H., Wang, L., Yang, C. Y., He, Y., Yang, W.et al.Huo, R. (2007). Heat transfer intensification using nanofluids. KONA, 25, 23-25.

Hussein, A. M., Bakar, R. A., Kadirgama, K., \& Sharma, K. V. (2013a). Experimental measurement of nanofluids thermal properties. International Journal of Automotive and Mechanical Engineering, 7(1), 850-863.

Hussein, A. M., Bakar, R. A., Kadirgama, K., \& Sharma, K. V. (2013b). Simulation study of turbulent convective heat transfer enhancement in heated tube flow using $\mathrm{TiO}_{2}$-water nanofluid. IOP Conference Series: Materials Science and Engineering, 50, 012035.

Hussein, A. M., Bakar, R. A., Kadirgama, K., \& Sharma, K. V. (2014). Heat transfer enhancement using nanofluids in an automotive cooling system. International Communications in Heat and Mass Transfer, 53, 195-202.

Hussein, A. M., Sharma, K. V., Bakar, R. A., \& Kadirgama, K. (2013). Heat transfer enhancement with nanofluids - a review. Journal of Mechanical Engineering and Sciences, 4, 452-461.

Kadirgama, K., Abou-El-Hossein, K. A., Noor, M. M., Sharma, K. V., \& Mohammad, B. (2011). Tool life and wear mechanism when machining hastelloy C-22HS. Wear, 270(3-4), 258-268. 
Kalidass, S., Palanisamy, P., \& Muthukumaran, V. (2012). Prediction of tool wear using regression and artificial neural network models in end milling of aisi 304 austenitic stainless steel. International Journal of Engineering and Innovative Technology,, 29-36.

Khan, M. A. R., Rahman, M. M., \& Kadirgama, K. (2012a). Mathematical model and optimization of surface roughness during electrical discharge machining of ti5al-2.5sn with graphite electrode. Advanced Science Letters, 15(1), 367-372.

Khan, M. A. R., Rahman, M. M., Kadirgama, K., \& Bakar, R. A. (2012b). Artificial neural network model for material removal rate of ti-15-3 in electrical discharge machining. Energy Education Science and Technology Part A: Energy Science and Research, 29(2), 1025-1038.

Khan, M. A. R., Rahman, M. M., Kadirgama, K., Maleque, M. A., \& Bakar, R. A. (2011). Artificial intelligence model to predict surface roughness of ti-15-3 alloy in edm process. World Academy of Science, Engineering and Technology, 74, 198-202.

Khan, M. A. R., Rahman, M. M., Kadirgama, K., Maleque, M. A., \& Ishak, M. (2011). Prediction of surface roughness of ti-6al-4v in electrical discharge machining: A regression model. Journal of Mechanical Engineering and Sciences, 1, 16-24.

Krajnik, P., Kopac, J., \& Sluga, A. (2005). Design of grinding factors based on response surface methodology. Journal of Materials Processing Technology, 162-163, 629-636.

Malkin, S., \& Guo, C. (2007). Thermal analysis of grinding. . CIRP Annals Manufacturing Technology,56, 760-761.

Najiha, M. S., Rahman, M. M., Kamal, M., Yusoff, A. R., \& Kadirgama, K. (2012). Minimum quantity lubricant flow analysis in end milling processes: A computational fluid dynamics approach. Journal of Mechanical Engineering and Sciences, 3, 340-345.

Najiha, M. S., Rahman, M. M., \& Yusoff, A. R. (2013). Modeling of the end milling process for aluminum alloy aa6061t6 using hss tool. International Journal of Automotive and Mechanical Engineering, 8, 1140-1150.

Najiha, M. S., Rahman, M. M., Yusoff, A. R., \& Kadirgama, K. (2012). Investigation of flow behavior in minimum quantity lubrication nozzle for end milling processes. International Journal of Automotive and Mechanical Engineering, 6(1), 768776.

Noor, M. M., Kadirgama, K., Habeeb, H. H., Rahman, M. M., \& Mohammad, B. (2010). Performance of carbide cutting tools when machining of nickel based alloy. International Journal of Material Forming, 3(SUPPL. 1), 475-478.

Rahman, M. M., \& Kadirgama, K. (2014). Performance of water-based zinc oxide nanoparticle coolant during abrasive grinding of ductile cast iron. Journal of Nanoparticles, 2014, 175896, 1-7.

Rahman, M. M., Khan, M. A. R., Kadirgama, K., Noor, M. M., \& Bakar, R. A. (2010). Modeling of material removal on machining of Ti-6Al-4V through edm using copper tungsten electrode and positive polarity. World Academy of Science, Engineering and Technology, 71, 576-581.

Rahman, M. M., Khan, M. A. R., Kadirgama, K., Noor, M. M., \& Bakar, R. A. (2011a). Experimental investigation into electrical discharge machining of stainless steel 304. Journal of Applied Sciences, 11(3), 549-554.

Rahman, M. M., Khan, M. A. R., Kadirgama, K., Noor, M. M., \& Bakar, R. A. (2011b) Optimization of machining parameters on tool wear rate of ti-6al-4v through 
edm using copper tungsten electrode: A statistical approach. Advanced Materials Research, 152-153, 1595-1602.

Rahman, M. M., Yusoff, A. R., \& Kadirgama, K. (2012). Investigation of flow behavior in minimum quantity lubrication nozzle for end milling processes. International Journal of Automotive and Mechanical Engineering, 6, 768-776.

Yusoff, A. R., Mohamed Suffian, M. R. Z., \& Taib, M. Y. (2011). Literature review of optimization technique for chatter suppression in machining. Journal of Mechanical Engineering and Sciences, 1, 47-61. 